\section{RMD Open}

Rheumatic \&

Musculoskeletal Diseases

\title{
Ankylosing spondylitis and mortality following hospitalised pneumonia: a population-based cohort study
}

\author{
Mette Holland-Fischer (D) , ${ }^{1}$ Reimar W Thomsen, ${ }^{2}$ Ulrik Tarp, ${ }^{3}$ Mette Nørgaard ${ }^{2}$
}

To cite: Holland-Fischer M, Thomsen RW, Tarp U, et al. Ankylosing spondylitis and mortality following hospitalised pneumonia: a populationbased cohort study. RMD Open 2020;6:e001140. doi:10.1136/ rmdopen-2019-001140

- Additional material is published online only. To view please visit the journal online (http://dx.doi.org/10.1136/ rmdopen-2019-001140).

Received 3 November 2019 Revised 30 December 2019 Accepted 19 January 2020

Check for updates

(C) Author(s) (or their employer(s)) 2020. Re-use permitted under CC BY-NC. No commercial re-use. See rights and permissions. Published by BMJ.

${ }^{1}$ Department of Rheumatology, Aalborg University Hospital, Aalborg, Denmark ${ }^{2}$ Department of Clinical Epidemiology, Aarhus University Hospital, Aarhus, Denmark ${ }^{3}$ Department of Rheumatology, Aarhus University Hospital, Aarhus, Denmark

Correspondence to Dr Mette Holland-Fischer; mhf@rn.dk

\section{ABSTRACT}

Objective Little is known about the prognosis of infections in patients with ankylosing spondylitis (AS) compared with patients without AS. The purpose of this study was to examine whether AS is associated with poorer outcomes in patients who are hospitalised with pneumonia.

Methods In a population-based cohort study including patients with hospitalised pneumonia with and without AS, we compared 90-day rates of mortality, all-cause readmission (90 days post-discharge) and pulmonary complications including pulmonary embolism, empyema and pulmonary abscess. We used Cox regression analyses to compute crude and adjusted HRs while adjusting for sex, age and level of comorbidity.

Results A total of 387796 patients (median age 71 years) were hospitalised for pneumonia in Denmark between 1997 and 2017. Among these, 842 (0.2\%) had AS (median age 65 years). The 90 -day mortality was $12.5 \%$ in patients with AS and $15.5 \%$ in patients with non-AS pneumonia, with crude and adjusted 90 -day HRs of $0.79(95 \% \mathrm{Cl} 0.66$ to 0.96$)$ and 0.95 (95\% $\mathrm{Cl} 0.79$ to 1.16$)$, respectively. The 90-day post-discharge readmission rate was $27.3 \%$ in patients with AS and $25.4 \%$ in patients without AS, with a corresponding adjusted readmission HR of 1.12 (95\% $\mathrm{Cl} 0.98$ to 1.27). Relative risk of pulmonary complications among patients with AS compared with patients without AS decreased over the study period, with adjusted HRs of 1.63 $(95 \%$ Cl 0.82 to 3.27$)$ in $1997-2006$ falling to 0.62 (95\% $\mathrm{Cl} 0.31$ to 1.23 ) in 2007-2017.

Conclusions AS is not associated with increased mortality following hospitalisation for pneumonia. Furthermore, no increased risk of readmission or pulmonary complications in patients with AS was detected in recent study years.

\section{INTRODUCTION AND AIMS}

Ankylosing spondylitis (AS) is a chronic inflammatory rheumatic disease often diagnosed in young age and with average age at disease onset of 24.8 years. ${ }^{1}$ AS is associated with increased mortality compared with general population members of similar age. ${ }^{23}$ Previous studies have found this fact to be related to an increased cardiovascular and cerebrovascular mortality, but also to an increased risk of death from infections including respiratory tract infections. ${ }^{45}$
Key messages

What is already known about this subject?

- Ankylosing spondylitis is associated with increased mortality compared with general population members of similar age.

- A highly increased risk of respiratory infections among patients with ankylosing spondylitis has been reported, and this may add to an increased risk of death.

What does this study add?

- Patients with ankylosing spondylitis did not exhibit an increased mortality or increased risk of readmission following hospitalisation with pneumonia.

- Furthermore, an initially elevated risk for pulmonary complications in patients with ankylosing spondylitis decreased over time.

How might this impact on clinical practice?

- Reassuringly, current management of pneumonia in patients with ankylosing spondylitis appears appropriate.

A highly increased risk of respiratory infections among patients with AS was reported (OR 5.83, 95\% CI 3.38 to 10.1 ) in a German study comparing the cumulative prevalence of self-reported infections in the previous 12 months among 1080 patients with AS and 102 patients with disc herniation. ${ }^{6}$ In contrast, little is known about the prognosis of infections in patients with AS compared with members of the general population without AS. It therefore remains unclear if the increased risk of dying from respiratory and other infections in AS can be explained solely by an increased risk of acquiring infections, or if patients with AS have worse infection outcomes as well.

Pneumonia remains a common cause of morbidity and mortality worldwide. A study from 2013 showed that pneumonia hospitalisations in Denmark increased from 4.96/1000 population in 1997 to 8.09 in 2011. The mortality following hospitalised 
Table 1 Characteristics of patients with and without ankylosing spondylitis (AS) who were hospitalised for pneumonia from 1997 to 2016 in Denmark

\begin{tabular}{|c|c|c|}
\hline & $\begin{array}{l}\text { AS } \\
\mathrm{N}(\%)\end{array}$ & $\begin{array}{l}\text { Non-AS } \\
\text { N (\%) }\end{array}$ \\
\hline $\mathrm{N}$ & $842(0.2)$ & $386.954(99.8)$ \\
\hline Age, median (IQR) & $65(52-74)$ & $71(57-81)$ \\
\hline $16-29$ years & $22(2.6)$ & $15.965(4.1)$ \\
\hline 30-44 years & $102(12.1)$ & $35.690(9.2)$ \\
\hline $45-59$ years & $195(23.2)$ & $58.375(15.1)$ \\
\hline $60-74$ years & $316(37.5)$ & $111.667(28.9)$ \\
\hline 75 years and above & $207(24.6)$ & $165.247(42.7)$ \\
\hline \multicolumn{3}{|l|}{ Sex } \\
\hline Female & $218(25.9)$ & $190.532(49.2)$ \\
\hline Male & $624(74.1)$ & $196.422(50.8)$ \\
\hline Pneumonia 1997-2006 & $274(0.2)$ & $161.597(99.8)$ \\
\hline Pneumonia 2006-2017 & $568(0.3)$ & $224.500(99.7)$ \\
\hline \multicolumn{3}{|c|}{ Comorbidity within 10 years before pneumonia } \\
\hline Congestive heart failure & $97(11.5)$ & $30.946(8.0)$ \\
\hline Peripheral vascular disease & $66(7.8)$ & $26.598(6.9)$ \\
\hline $\begin{array}{l}\text { Previous myocardial } \\
\text { infarction }\end{array}$ & $48(5.7)$ & $20.386(5.3)$ \\
\hline Chronic pulmonary disease & $152(18.1)$ & $60.981(15.8)$ \\
\hline Cerebrovascular disease & $91(10.8)$ & $48.986(12.7)$ \\
\hline Hemiplegia & $19(2.7)$ & $1.917(0.5)$ \\
\hline Dementia & $7(0.8)$ & $13.304(3.4)$ \\
\hline Connective tissue disease & $79(9.4)$ & $9.834(2.5)$ \\
\hline Peptic ulcer disease & $54(6.4)$ & $17.479(4.5)$ \\
\hline Diabetes type I and II & $77(9.1)$ & $30.399(7.8)$ \\
\hline $\begin{array}{l}\text { Diabetes with end organ } \\
\text { damage }\end{array}$ & $46(5.5)$ & $17.004(4.4)$ \\
\hline $\begin{array}{l}\text { Moderate to severe renal } \\
\text { disease }\end{array}$ & $45(5.3)$ & $13.961(3.6)$ \\
\hline Any tumour & $98(11.6)$ & $52.629(13.6)$ \\
\hline Leukaemia & $5(0.6)$ & $3.484(0.9)$ \\
\hline Lymphoma & $13(1.5)$ & $6.205(1.6)$ \\
\hline Metastatic solid tumour & $18(2.1)$ & $9.365(2.4)$ \\
\hline Mild liver disease & $16(1.9)$ & $5.636(1.5)$ \\
\hline $\begin{array}{l}\text { Moderate-to-severe liver } \\
\text { disease }\end{array}$ & $2(0.2)$ & $1.72(0.45)$ \\
\hline AIDS & 0 & $545(0.1)$ \\
\hline \multicolumn{3}{|c|}{ Comorbidity index (level of Charlson Index Score) } \\
\hline Low (0) & $350(41.6)$ & $180.629(46.8)$ \\
\hline Medium (1-2) & $316(37.5)$ & $137.850(35.7)$ \\
\hline High $(\geq 3)$ & $176(20.1)$ & $67.934(17.6)$ \\
\hline $\begin{array}{l}\text { Duration of hospital stay in } \\
\text { days, median (IQR) }\end{array}$ & $6(3-11.5)$ & $7(4-12)$ \\
\hline
\end{tabular}

pneumonia is high and seems largely unchanged over decades. $^{7}$ To date, no population-based pneumonia cohort outcome study has focused on patients with AS.
Pre-existing lung disease is associated with poorer outcomes after pneumonia. ${ }^{8}{ }^{9}$ Studies have reported that lung disease including apical fibrosis, interstitial lung disease and chest wall abnormalities are associated with AS, and that chronic obstructive pulmonary disease (COPD) is more frequent among patients with AS than controls. $^{1011}$ Moreover, inflammatory disease activity and AS-related therapy might influence pneumonia outcomes.

We hypothesised that AS is associated with increased mortality, risk of complications and readmission in patients who are hospitalised with pneumonia. In addition, we wanted to explore if relative risks of these outcomes decreased over time in patients with AS versus patients without AS, and if AS disease activity and AS therapy influence the pneumonia prognosis.

\section{PATIENTS AND METHODS \\ Setting and study population}

We conducted a population-based cohort study in Denmark with approximately 5.8 million inhabitants. All Danish citizens are assigned a unique personal identification number (CPR) at birth or immigration which we used to cross-link data from different medical registries at the individual level. ${ }^{12}$ We used the Danish National Patient Register (DNPR) to identify patients with pneumonia. Since 1977, the DNPR has recorded all inpatient hospitalisations in the entire Danish population and since 1995 all instances of contact with hospital outpatient clinics. The DNPR records admission and discharge dates and up to 20 discharge diagnoses per contact coded according to the International Classification of Diseases, edition 10 (ICD-10) during the period of this study and ICD-8 during earlier periods. ${ }^{13}$ The records also include CPR numbers, patients' municipalities, identification of the hospital wards, and dates and times of activities performed, including information on the type of examinations, surgeries and treatments. We included all adult patients ( $\geq 16$ years) with a first-time primary hospital discharge diagnosis of pneumonia (for ICD-10 codes, please see online additional file 1) between January 1997 and 31 July 2017; thus, patients with a prior discharge diagnosis of pneumonia were excluded. A previous evaluation of the validity of the pneumonia diagnosis in DNPR found a positive predictive value (PPV) of $90 \%$ (95\% CI $82 \%$ to $95 \%)$. $^{14}$

\section{Data on AS}

Data on AS were obtained from the DNPR and DANBIO (for ICD codes, please see online additional file 1). While DANBIO contains information on subcohorts of patients with AS, all patients with AS seen in hospital clinics are registered in the DNPR. DANBIO is a nationwide, Danish register where clinical data on patients with rheumatic diseases are recorded. DANBIO was initiated in 2000 as a nationwide voluntary register, and in 2006 DANBIO was approved by the Danish National Board of Health as a national quality of care registry. ${ }^{15}$ Since then, it has been mandatory to register all patients with AS on biologics and 
Table 2 90-day all-cause mortality following hospitalisation with pneumonia in patients with or without ankylosing spondylitis (AS)

\begin{tabular}{|c|c|c|c|c|}
\hline & \multicolumn{2}{|c|}{ All-cause mortality at 90 days $\mathrm{N}(\%)$} & \multicolumn{2}{|c|}{ HRs 90-day mortality } \\
\hline & & & Crude & Adjusted* \\
\hline & AS & Non-AS & AS & AS \\
\hline $\begin{array}{l}\text { All patients hospitalised for } \\
\text { pneumonia 1997-2017† }\end{array}$ & $105(12.5)$ & $59.767(15.5)$ & 0.79 (0.66 to 0.96$)$ & $0.95(0.79$ to 1.16$)$ \\
\hline 1997-2006 & $38(13.9)$ & $25.208(15.6)$ & $0.88(0.64$ to 1.21$)$ & $1.03(0.75$ to 1.41$)$ \\
\hline 2007-2017† & $67(11.8)$ & $34.559(15.4)$ & $0.76(0.59$ to 0.96$)$ & $0.94(0.74$ to 1.20$)$ \\
\hline
\end{tabular}

HRs, including $95 \% \mathrm{Cls}$, calculated using Cox proportional-hazards regression analysis. Patients without AS used as reference group.

${ }^{*}$ Adjusted for sex, age and level of comorbidity before admission.

†Until 31 July 2017.

since 2015 all newly diagnosed patients with AS. Patients are registered in DANBIO, when they are seen by a rheumatologist in hospital or private outpatient clinics. The recorded information includes the current treatment, disease activity (see below), C reactive protein, functional status and visual analogue scale scores of pain, fatigue, and of the patient and physician's global assessment.

\section{Data on disease activity and functional status}

We obtained information on the latest registration of the Bath Ankylosing Spondylitis Disease Activity Index (BASDAI) from DANBIO. BASDAI combines information on morning stiffness, localised tenderness, fatigue and joint pain (reference), and in Denmark a score above 4 usually indicates that the patient is a candidate for treatment with biologics. The BASDAI has a good test-retest $(\mathrm{r}=0.93 ; \mathrm{p}<0.001)$ reliability, reflects the entire spectrum of disease and is sensitive to change. ${ }^{16}$

We used the Bath AS Functional Index (BASFI) as a measure of the patient's functional limitation and the Bath AS Metrology Index (BASMI) as a measure of the patient's axial status. BASMI has been found reproducible for both intraobserver $(\mathrm{r}=0.99, \mathrm{p}<0.001)$ and interobserver variability $(\mathrm{r}=0.97, \mathrm{p}<0.001)$ and sensitive to change. ${ }^{17}$ BASFI has been shown as a reliable tool in assessing function in patients with $\mathrm{AS}$ and is able to capture changes across the whole spectrum of disease. ${ }^{18}$

\section{Data on medication}

Data on AS treatment were assessed from both DNPR and DANBIO. ${ }^{15}$ In the DNPR, treatment with diseasemodifying antirheumatic drugs (DMARDs) and biologics are coded in relation to visits at hospital outpatient clinics. For AS outpatient visits, the use and types of DMARDs and/or biologics are recorded. We retrieved DNPR information on all treatments registered within 12 months prior to pneumonia hospitalisation. For the subgroup of patients with pneumonia who were registered in the DANBIO database, we also retrieved information from the last visit within 12 months before the pneumonia hospitalisation. If the patient had more than one registration in $\mathrm{DANBIO}$ within that year, the latest visit data were used.
We categorised all patients with AS according to the type of preadmission AS medication into the following groups: treatment with DMARD (either as monotherapy or as DMARD combination therapy), anti-TNF alfa treatment as monotherapy, anti-TNF alfa treatment in combination with one or more DMARDs, and no recorded AS therapy. The patients were categorised according to the last registered treatment type before the pneumonia hospitalisation.

\section{Comorbidity data}

We obtained information on the 19 conditions included in the Charlson Comorbidity Index recorded within 10 years before the pneumonia hospitalisation from the DNPR. A previous study found the coding in the DNPR for the 19 Charlson conditions to have an overall PPV of $98 \%{ }^{19}$ In addition, the index has previously been validated as a predictor of 1-year mortality following hospitalisation. ${ }^{2021}$ We did not include the AS diagnosis when we computed the Charlson Comorbidity Index score, and we categorised the scores into three levels: score of 0 , low; score of 1-2, medium; score of $3+$, high.

\section{Pneumonia outcomes}

Death from any cause within 90 days from the pneumonia hospitalisation was a main study outcome. We ascertained the exact date of eventual death from the Danish Civil Registration System. ${ }^{12}$ Other outcomes were all-cause readmission rate within 90 days after initial pneumonia hospitalisation discharge, and hospital diagnoses of pulmonary complications associated with the initial hospitalisation or up to 90 days after the admission date. We defined complications as pulmonary embolism, empyema or pulmonary abscess (please see online supplementary appendix for ICD-10 codes). Information on both readmission and pulmonary complications were obtained from the DNPR.

\section{Statistical analysis}

Pneumonia prognosis in patients with AS versus patients without AS

We followed all patients with pneumonia from the date of pneumonia admission until death, migration or 90 days after the discharge date, whichever came first. We 


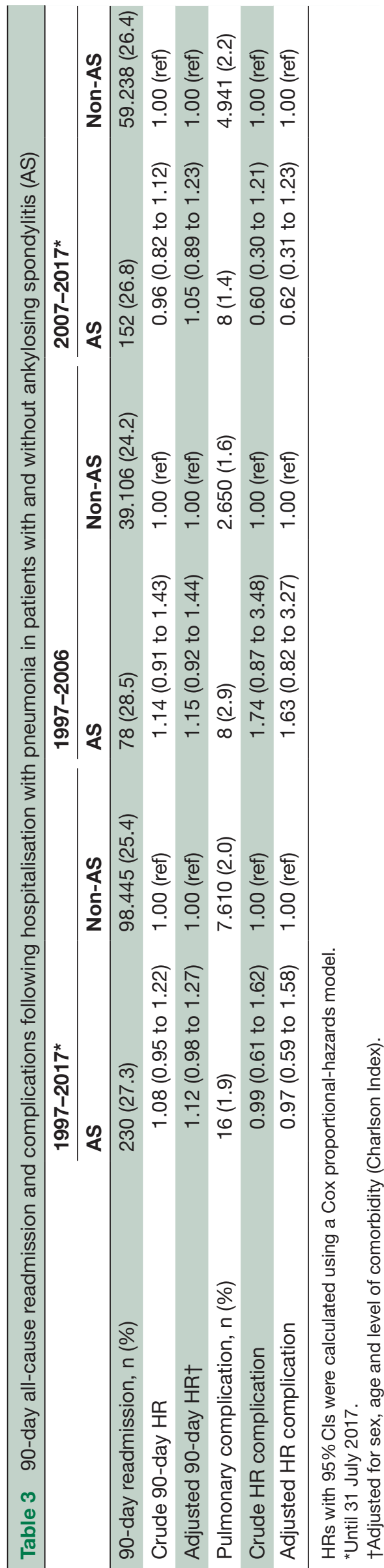

estimated mortality, rates for readmission and pulmonary complications after 90 days for patients with AS and patients without AS. Cox regression was used to compute crude and adjusted HRs for death, readmission and pulmonary complications within 90 days following admission for pneumonia while comparing patients with AS and those without AS, controlling for age, sex and level of comorbidities. In order to evaluate if the prognostic impact of AS on pneumonia changed over time, we stratified the analysis by calendar time for pneumonia diagnosis (1997-2006 and 2007-2017).

Prognostic effect of AS disease activity and therapy among patients with AS

Internally among patients with pneumonia with AS, we compared 90-day mortality between high and low levels of preadmission BASDAI (reference: BASDAI $<4$ ), BASFI (reference: BASFI <4) and BASMI (reference BASMI $<4)$. We also compared 90-day mortality associated with the different treatment categories, using 'no treatment' as reference. We used Cox regression while adjusting for sex, age and level of comorbidities.

Statistical analyses were performed using the Stata V.12.1 statistical software package (StataCorp, College Station, TX, USA). We presented HRs as point estimates with $95 \%$ CIs.

\section{RESULTS}

A total of 387796 patients were hospitalised for pneumonia between 1997 and 2017. Among these 842 (0.2\%) had AS. As expected, the proportion of men was higher among patients with AS (74.1\%) than among patients without AS (50.8\%) (table 1). Patients with AS were younger (median age 65 vs 71 years) and had higher comorbidity including higher prevalence of chronic lung disease. Among patients with AS, $57.6 \%$ had one or more comorbidities compared with $53.3 \%$ among patients without AS. The median duration of hospital stay for patients with AS was 6(3-15) days compared with 7(4-12) days for patients without AS.

\section{Mortality in patients with AS versus patients without AS}

We found a 90-day mortality in patients with pneumonia with AS of $12.5 \%$ compared with $15.5 \%$ in patients with non-AS pneumonia. Corresponding crude 90 -day HR was 0.79 (95\% CI 0.66 to 0.96 ). After adjustment for differences in age the HR increased to 1.07 (95\% CI 0.88 to 1.29 ), and with further adjustment for sex and comorbidity, the HR was 0.95 (95\% CI 0.79 to 1.16 ) (table 2).

Among patients without AS, the 90-day pneumonia mortality remained steady across the two calendar periods with rates of $15.6 \%$ and $15.4 \%$, while the 90 -day mortality in patients with AS tended to be highest in the first period with a rate of $13.9 \%$ compared with $11.8 \%$ in the second period. When comparing the 90-day mortality between patients with AS and patients without AS, we found adjusted HRs of 1.03 (95\% CI 0.75 to 1.41) in the 
first period $1997-2006$ and 0.94 (95\% CI 0.74 to 1.20$)$ in the second period 2007-2017.

\section{Readmission and pulmonary complications in patients with AS versus patients without AS}

Among the patients with AS, $27.3 \%$ were readmitted within 90 days after discharge compared with $25.4 \%$ of the patients without AS. The corresponding crude 90-day post-discharge HR for readmission was 1.08 (95\% CI 0.95 to 1.22), and the adjusted HR was 1.12 (95\% CI 0.98 to 1.27). The readmission rate among patients with AS patients was slightly lower in the second period (26.8\%) than in the first $(28.5 \%$ ) (table 3), resulting in adjusted HRs of readmission associated with AS of 1.15 (95\% CI 0.92 to 1.44 ) in the first period and 1.05 (95\% CI 0.89 to 1.23) in the second period. The risk of pulmonary complications among patients with AS compared with patients without AS decreased more clearly over time, with adjusted HRs of complications for the first and second periods of 1.63 (95\% CI 0.82 to 3.27 ) and 0.62 (95\% CI 0.31 to 1.23 ), respectively.

\section{Prognostic effect of AS functional status, disease activity and therapy}

Prior to admission, 185 (22\%) of the patients with AS had at least one registration in DANBIO. In 133 patients, the last registration was within 1 year prior to admission (table 4). The proportion of men was $70.8 \%$, similar to the entire cohort, while the patients in DANBIO were slightly younger than in the entire cohort of patients with AS with a median age of 55 (43-65).

BASDAI measurements within 1 year prior to admission were available for 110 patients. Compared with the group with low BASDAI $(<4)$, we found crude and adjusted 90-day HR for mortality with BASDAI $>4$ of 1.00 (95\% CI 0.95 to 1.05 ) and 0.99 (95\% CI 0.94 to 1.05 ), respectively. BASFI measurements were available for 109 patients. Compared with the group with low BASFI $(<4)$, crude and adjusted 90-day HR for mortality with BASFI $>4$ were 1.03 (95\% CI 0.97 to 1.08$)$ and 1.02 (95\% CI 0.96 to 1.09), respectively. BASMI measurements were available for 70 patients. Compared with the group with low BASMI $(<4)$, we found crude and adjusted 90-day HR for mortality with BASMI $>4$ of 1.01 (95\% CI 0.96 to 1.06 ) and 0.99 (95\% CI 0.94 to 1.05 ), respectively.

Among the patients with AS, 18 (2\%) were treated with one or more DMARDS, $87(10.3 \%)$ were treated with anti-TNF alfa monotherapy and $44(5.2 \%)$ received a combination of anti-TNF alfa and DMARDs. Among nontreated patients, $68 \%$ were 60 years or older compared with patients treated with either anti-TNF alfa monotherapy or in combination with DMARDs, of which $33 \%$ and $27 \%$ were 60 years or older, respectively. Among patients treated with DMARDs, 55\% were 60 years or older and in this group $50 \%$ were women-while in all other groups approximately $70 \%$ were men. The 90 -day mortality was higher among non-treated $(13.6 \%)$ than patients treated with DMARD $(5.6 \%)$, anti-TNF $(5.8 \%)$
Table 4 Characteristics of patients with ankylosing spondylitis who were hospitalised for pneumonia from 1997 to 2016 in Denmark and registered in DANBIO

\begin{tabular}{|c|c|c|}
\hline & $\begin{array}{l}\text { Registration in } \\
\text { DANBIO at any } \\
\text { time prior to the } \\
\text { hospitalisation for } \\
\text { pneumonia }\end{array}$ & $\begin{array}{l}\text { Registration in } \\
\text { DANBIO 0-12 } \\
\text { months prior to the } \\
\text { hospitalisation for } \\
\text { pneumonia }\end{array}$ \\
\hline $\mathrm{N}$ & 185 & 133 \\
\hline Age, median (IQR) & $53.8(43-65)$ & $52.2(42-62)$ \\
\hline $16-29$ years $(\%)$ & $10(5.4)$ & $6(4.5)$ \\
\hline $30-44$ years $(\%)$ & $44(23.8)$ & $34(25.6)$ \\
\hline $45-59$ years $(\%)$ & $60(32.4)$ & $52(39.1)$ \\
\hline $60-74$ years $(\%)$ & $56(30.3)$ & $33(24.8)$ \\
\hline 75 years and above & $15(8.1)$ & $8(6.0)$ \\
\hline \multicolumn{3}{|l|}{ Sex } \\
\hline Female (\%) & $54(29.2)$ & $38(28.6)$ \\
\hline Male (\%) & $131(70.8)$ & $95(71.4)$ \\
\hline \multicolumn{3}{|c|}{ Year of pneumonia hospitalisation } \\
\hline $1997-2006$ & 8 & 8 \\
\hline 2006-2017 & 177 & 125 \\
\hline \multicolumn{3}{|c|}{ Comorbidity index (Charlson Index Score) } \\
\hline Low (0) & $103(55.7)$ & $80(60.2)$ \\
\hline Medium (1-2) & $54(29.2)$ & $35(26.3)$ \\
\hline High $(\geq 3)$ & $28(15.1)$ & $18(13.5)$ \\
\hline $\begin{array}{l}\text { Patients with BASDAI } \\
\text { available (\%) }\end{array}$ & $148(80.0)$ & $110(82.7)$ \\
\hline $\begin{array}{l}\text { BASDAI }<4 \text { ( } \% \text { of } \\
\text { available) }\end{array}$ & $66(44.5)$ & $51(46.4)$ \\
\hline $\begin{array}{l}\text { Patients with BASFI } \\
\text { available (\%) }\end{array}$ & 146 (78.9) & 109 (82.0) \\
\hline $\begin{array}{l}\text { BASFI }<4 \text { ( } \% \text { of } \\
\text { available) }\end{array}$ & $62(42.5)$ & $52(47.7)$ \\
\hline $\begin{array}{l}\text { Patients with BASMI } \\
\text { available (\%) }\end{array}$ & 95 (51.4) & 70 (52.6) \\
\hline $\begin{array}{l}\text { BASMI }<4 \text { ( } \% \text { of } \\
\text { available) }\end{array}$ & 49 (51.7) & 39 (55.7) \\
\hline
\end{tabular}

BASDAI, Bath Ankylosing Spondylitis Disease Activity Index; BASFI, Bath AS Functional Index; BASMI, Bath AS Metrology Index.

or anti-TNF alfa and DMARD in combination (6.8\%), respectively. The low number of exposed hampered our ability to adjust for potential confounding factors. Neither anti-TNF alfa monotherapy, treatment with DMARDs nor anti-TNF alfa therapy in combination with one or more DMARDS were associated with increased mortality (table 5).

\section{DISCUSSION}

In this population-based study including 842 patients with AS and more than 350000 patients without AS hospitalised due to pneumonia, patients with AS did not have higher mortality, complications and readmission rates than patients without AS after adjustment for confounding factors. 
Table 5 All-cause mortality in patients with AS following hospitalisation for pneumonia according to preadmission as therapy

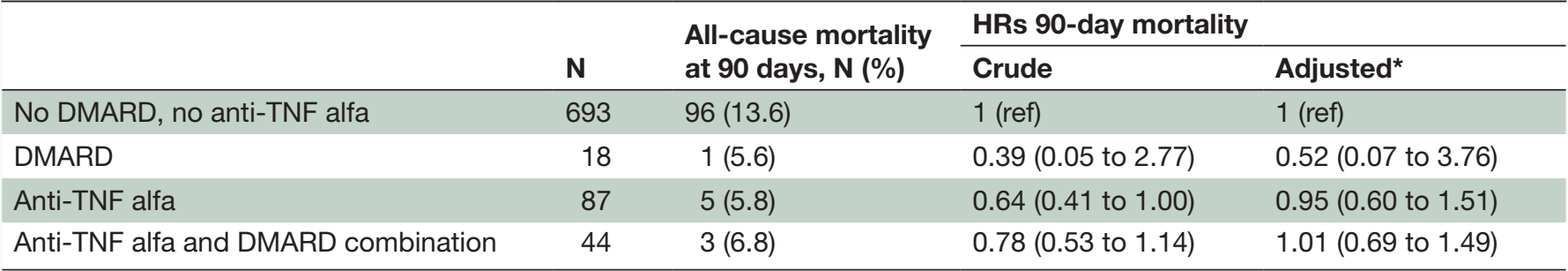

HRs, including 95\% Cls, were calculated using a Cox proportional-hazards model.

${ }^{*}$ Adjusted for sex, age and level of comorbidity before admission.

AS, ankylosing spondylitis; DMARD, disease-modifying antirheumatic drug; TNF, tumour necrosis factor.

Lung disease is associated with AS. This includes chronic apical fibrosis, interstitial lung disease and chest wall abnormalities. ${ }^{1011}$ A recent study from Israel including 4076 patients with AS and 20290 age-matched and sexfrequency-matched controls found a higher proportion of COPD in patients with AS than in controls (46\% vs $18 \%) .{ }^{11}$ We found only a slightly higher prevalence of COPD among our patients with AS than in the patients with non-AS pneumonia ( $18 \%$ vs $15 \%$ ), but no increased crude pneumonia mortality versus non-AS individuals. In the study from Israel, the diagnoses of COPD is based on data derived from both hospital and primary care physicians' clinical records, while our study included records from hospitals and not primary care physicians. It is likely that patients with one chronic disease like AS are more likely to see their physician on a regular basis and therefore more likely to be diagnosed with COPD even in case of very mild symptoms. This is in contrast to patients either referred to hospital with COPD or diagnosed with COPD at hospitals, who are more likely to suffer from more severe COPD.

The AS pneumonia mortality was slightly higher in the first half of our study period (1997-2006) than in the second period (2007-2017). This may be partly caused by the fact that predominantly patients with AS with severe AS disease were seen at hospitals in the beginning of our study period and thus registered with a diagnosis of AS in the DNPR. In the second period (2007-2017), biologics were commonly used for AS and the new treatment strategies likely resulted in patients with AS being more commonly hospital registered, but also treated more efficiently. It is also possible that prednisolone was used more frequently in the first period and that this may have affected the outcome following pneumonia. Unfortunately, we lacked information on use of prednisolone so we could not address this any further.

The strengths of this study include the accuracy and the size of the data sources used. Complete follow-up data from detailed, high-quality registries allowed for extensive control of confounders. Both selection and recall bias were limited because of the prospectively recorded population-based data independently of our research question. We were able to adjust for a broad range of comorbidities using the Charlson Index, but not for lifestyle factors, such as smoking and body mass index. Since smoking is a major contributor to the risk and severity of COPD, the patients with AS might be more likely to be smokers, but the proportion of patients with AS with COPD was only slightly increased and this could not have substantially affected our results.

The identification of patients with AS through the DNPR may have excluded patients with AS with mild disease (ie, patients who were never treated at a hospital clinic or were admitted for another illness only without concomitant registration of AS in the DNPR). There is, however, no reason to suspect that their mortality should be higher following pneumonia hospitalisation than those of the patients with AS that we captured by our data sources.

Patients with AS receiving DMARDs and/or anti-TNF alfa therapy are closely monitored in the outpatient clinic and may be hospitalised earlier and/or more frequently in case of suspected infection than patients being managed without these treatments. Accordingly, at time of pneumonia hospitalisation, patients with AS receiving DMARDs and/or anti-TNF alfa therapy may be less seriously affected by the pneumonia which may result in a lower mortality.

Neither anti-TNF alfa monotherapy, treatment with DMARDs, nor anti-TNF alfa therapy in combination with one or more DMARDS were associated with increased pneumonia mortality in this study. However, the low number of drug-exposed patients and outcome events hampered our ability to adjust for all potential confounding factors, and these results should be interpreted with caution.

Patients with AS with high disease activity, decreased functional status or poorer axial status could have a poorer outcome of pneumonia than the average patient with AS. DANBIO data allowed us to identify patients with AS who potentially had high disease activity, decreased functional status and poor axial status at time of pneumonia diagnosis. We thus find it reassuring that these patients did not have high mortality following pneumonia, even if they only represent a minor part of the AS study population.

Recent studies have indicated that non-steroidal anti-inflammatory drug (NSAID) exposure at the early stage of community-acquired pneumonia is associated with a more complicated course and worse outcomes, 
probably because NSAIDs mask initial symptoms and delay therapy. ${ }^{22}{ }^{23}$ It is likely that a large proportion of patients with AS in our study received NSAIDs since NSAIDs are first-line treatment in AS. Unfortunately, we lacked information on use of NSAIDs, and we were thus unable to examine whether pneumonia prognosis varied by use of these drugs. However, we did not find an increased mortality among patients with AS compared with patients without AS, which makes it unlikely that NSAID causes significantly increased mortality among patients with AS following pneumonia.

\section{Conclusions}

Despite the well-known association between AS and lung disease, our study, to our knowledge, is the first to investigate the influence of AS on the prognosis of pneumonia. Reassuringly, we found no increased pneumonia mortality among patients with AS. In addition, no increased risk of pneumonia complications or readmission was detected in patients with AS in recent years.

Contributors All authors formulated the scientific problem, interpreted the results and finalised the manuscript. MH-F was responsible for data collection and subsequent analysis. MH-F, RWT and MN developed the methods, and planned the experiments and methodology. MH-F wrote the first draft. All authors approved the final manuscript.

Funding The study received an unrestricted grant from the Danish Rheumatism Association (Gigtforeningen), grant no. A2225.

Competing interests None declared.

Patient consent for publication Not required.

Ethics approval The study was approved by the Danish Data Protection Agency (record no. 2008-58-0028).

Provenance and peer review Not commissioned; externally peer reviewed.

Data availability statement Data are available on reasonable request to the corresponding author.

Open access This is an open access article distributed in accordance with the Creative Commons Attribution Non Commercial (CC BY-NC 4.0) license, which permits others to distribute, remix, adapt, build upon this work non-commercially, and license their derivative works on different terms, provided the original work is properly cited, appropriate credit is given, any changes made indicated, and the use is non-commercial. See: http://creativecommons.org/licenses/by-nc/4.0/.

ORCID iD

Mette Holland-Fischer http://orcid.org/0000-0002-7628-7613

\section{REFERENCES}

1 Feldtkeller E, Khan M, van der Heijde D, et al. Age at disease onset and diagnosis delay in HLA-B27 negative vs. positive patients with ankylosing spondylitis. Rheumatol Int 2003;23:61-6.

2 Exarchou S, Lie E, Lindström U, et al. Mortality in ankylosing spondylitis: results from a nationwide population-based study. Ann Rheum Dis 2016;75:1466-72.
3 Lehtinen K. Mortality and causes of death in 398 patients admitted to hospital with ankylosing spondylitis. Ann Rheum Dis 1993;52:174-6.

4 Haroon NN, Paterson JM, Li P, et al. Patients with ankylosing spondylitis have increased cardiovascular and cerebrovascular mortality: a population-based study. Ann Intern Med 2015;163:409-16.

5 Prati C, Puyraveau M, Guillot X, et al. Deaths associated with ankylosing spondylitis in France from 1969 to 2009. J Rheumatol 2017:44:594-8

6 Zochling J, Bohl-Bühler MHJ, Baraliakos X, et al. The high prevalence of infections and allergic symptoms in patients with ankylosing spondylitis is associated with clinical symptoms. Clin Rheumatol 2006;25:648-58.

7 Søgaard M, Nielsen RB, Schønheyder HC, et al. Nationwide trends in pneumonia hospitalization rates and mortality, Denmark 19972011. Respir Med 2014;108:1214-22.

8 Braeken DCW, Franssen FME, Schutte H, et al. Increased severity and mortality of CAP in COPD: results from the German competence network, CAPNETZ. Chronic Obs Pulm Dis 2015;2:131-40.

9 Ito A, Ishida T, Tokumasu $\mathrm{H}$, et al. Prognostic factors in hospitalized community-acquired pneumonia: a retrospective study of a prospective observational cohort. BMC Pulm Med 2017:17:78

10 Mercieca C, van der Horst-Bruinsma IE, Borg AA. Pulmonary, renal and neurological comorbidities in patients with ankylosing spondylitis; implications for clinical practice. Curr Rheumatol Rep 2014;16:434.

11 Sharif K, Watad A, Tiosano S, et al. The link between COPD and ankylosing spondylitis: a population based study. Eur J Intern Med 2018;53:62-5.

12 Schmidt M, Pedersen L, Sørensen HT. The Danish civil registration system as a tool in epidemiology. Eur J Epidemiol 2014;29:541-9.

13 Lynge E, Sandegaard JL, Rebolj M. The Danish national patient register. Scand J Public Health 2011;39:30-3.

14 Thomsen RW, Riis A, Nørgaard M, et al. Rising incidence and persistently high mortality of hospitalized pneumonia: a 10-year population-based study in Denmark. J Intern Med 2006;259:410-7.

15 Ibfelt EH, Jensen DV, Hetland ML. The Danish nationwide clinical register for patients with rheumatoid arthritis: DANBIO. Clin Epidemiol 2016;8:737-42.

16 Garrett S, Jenkinson T, Kennedy LG, et al. A new approach to defining disease status in ankylosing spondylitis: the Bath ankylosing spondylitis disease activity index. $J$ Rheumato 1994;21:2286-91.

17 Jenkinson TR, Mallorie PA, Whitelock HC, et al. Defining spinal mobility in ankylosing spondylitis (AS). The Bath AS Metrology index. $J$ Rheumatol 1994;21:1694-8.

18 Calin A, Garrett S, Whitelock H, et al. A new approach to defining functional ability in ankylosing spondylitis: the development of the Bath ankylosing spondylitis functional index. J Rheumatol 1994;21:2281-5.

19 Thygesen SK, Christiansen CF, Christensen S, et al. The predictive value of ICD-10 diagnostic coding used to assess Charlson comorbidity index conditions in the population-based Danish national registry of patients. BMC Med Res Methodol 2011;11:83

20 de Groot V, Beckerman H, Lankhorst GJ, et al. How to measure comorbidity. A critical review of available methods. J Clin Epidemiol 2003;56:221-9.

21 Charlson ME, Pompei P, Ales KL, et al. A new method of classifying prognostic comorbidity in longitudinal studies: development and validation. J Chronic Dis 1987;40:373-83.

22 Voiriot G, Dury S, Parrot A, et al. Nonsteroidal antiinflammatory drugs may affect the presentation and course of communityacquired pneumonia. Chest 2011;139:387-94.

23 Messika J, Sztrymf B, Bertrand F, et al. Risks of nonsteroidal antiinflammatory drugs in undiagnosed intensive care unit pneumococcal pneumonia: younger and more severely affected patients. J Crit Care 2014;29:733-8. 